Portland State University

PDXScholar

\title{
Leaders of Global Virtual Teams: Implications for the Identification and Training of Successful E-Leaders
}

Janae R. Rainbolt

Portland State University

Follow this and additional works at: https://pdxscholar.library.pdx.edu/honorstheses

Let us know how access to this document benefits you.

\section{Recommended Citation}

Rainbolt, Janae R., "Leaders of Global Virtual Teams: Implications for the Identification and Training of Successful E-Leaders" (2019). University Honors Theses. Paper 782.

https://doi.org/10.15760/honors.800

This Thesis is brought to you for free and open access. It has been accepted for inclusion in University Honors Theses by an authorized administrator of PDXScholar. Please contact us if we can make this document more accessible: pdxscholar@pdx.edu. 
Leaders of global virtual teams:

Implications for the identification and training of successful e-leaders

By

Janae Rainbolt

An undergraduate honors thesis submitted in partial fulfillment of the

Requirements for the degree of

Bachelor of Science

In

University Honors

And

Business Administration: Management and Leadership

Thesis Advisor

David E. Caughlin

Portland State University

2019 


\begin{abstract}
The business environment is an ever-evolving enterprise, and as technology advances so do their operations, allowing for more businesses to become global. This increase in globalization has led to the problem of how to manage these activities around the world. Virtual teams have become one solution, but they present their own challenges in regards to how to effectively manage a team that is culturally diverse and lives in various times zones. Through the analysis of 91 research articles and texts on the topic of e-leadership, this research identifies the most prevalent indicators of the management practices of leaders of efficacious global virtual teams (GVT). This thesis found that trust, cultural intelligence, communication, leadership styles, and technology are key for GVT leadership. These indicators have been linked to personality characteristics for traditional teams and multinational teams. This review will form the proposal for an empirical investigation into the validity of these frameworks towards the study of e-leadership in GVTs.

Keywords: e-leaders, global virtual teams, virtuality, trust, cultural intelligence, transformational leadership, technology
\end{abstract}




\section{Leaders of global virtual teams:}

\section{Implications for the identification and hiring of successful e-managers}

The business environment is an ever-evolving enterprise and as technology advances so do their operations, allowing for more businesses to become global. This increase in globalization has led to the problem of how to manage these activities around the world. One solution was the creation of virtual teams because they offer greater adaptability and versatility to meet business demands. Global operations increase the challenges faced by these teams because they have various time zones and increased cultural diversity.

Members of global virtual teams (GVTs) are geographically dispersed in order to handle the new challenges that come from operating globally. In this review, the term "virtual team" is not synonymous with GVT; rather, a virtual team operates virtually but can be composed of members within the same country and often the members are culturally similar. The research in the realm of virtual teams sometimes use these terms interchangeably but this review recognizes the distinct difference between GVTs and virtual teams. The research on both can arguably be generalized to each other in terms of challenges of interacting through technology, leading and lack of interpersonal interaction but this review adds value by addressing the additional demands of leading a GVT. The working definition of GVTs utilized for this research is a team consisting of organizationally, geographically, and/or time dissipated members whose tasks are reliant on the utilization of communication technology (Hosseini, \& Chileshe, 2013).

GVTs have the potential to provide organizations with a powerful tool to be more flexible in keeping up with rapid changes in the business environment (Mockaitis, Zander \& De Cieri, 2018). A recent survey of 1,620 business respondents from 90 countries found that $89 \%$ worked on at least one virtual team and $62 \%$ stated they work on a team with three or more cultures 
(RW3 CultureWizard, 2016). While virtual teams assist in creating a positive climate of diversity, they also present their own predicaments in regards to how to effectively lead a team that is culturally diverse and works in various times zones (Mockaitis et al., 2018).

GVTs can be used as an organizational resource, they can increase the exchange of information and knowledge and develop ties through the interaction of team members (Mockaitis et al., 2018). Team members share global business knowledge such as respective trade markets, organizational practices, bureaucratic processes at each location, and this knowledge can then be disseminated to different business locations (Mockaitis et al., 2018). Leaders that are well adapted to working with face-to-face (F2F) teams may not be able to translate these skills in a virtual setting. They may find things like coaching, motivating, and managing a virtual team to achieve high performance difficult to accomplish without F2F interaction (Edison, 2011). The difference in leading virtual teams versus F2F teams is an area of literature that is underdeveloped and presents a more arduous task for their e-managers, and an indisputable fact of GVTs is they have a need for productive management (Hosseini, Zou, Chileshe \& Baroudi, 2013).

The issues faced by GVT leaders versus virtual team leaders hang on two key elements time zones and cultural differences - that can have a positive impact on team relations, communication, and coordination (Lee-Kelley \& Sankey, 2008). Leadership theories and practices have been investigated in the management literature, but in many cases, the question still remains whether findings can be generalized to virtual teams. The leadership theory studies for virtual teams are not nearly as expansive as those for F2F teams; further, although the focus of studies on GVTs identify the challenges and necessities to lead an e-team, few offer strategies directed to the e-leader. A number of investigations have focused on relatively stable attributes 
of leaders, such as personality characteristics; these attributes have been correlated with effective leadership, but limited research has invested which personality characteristics predict and explain various e-leadership behaviors.

In the present paper, I review the extant literatures (and their intersections) on virtual teams, GVTs, leadership, team-leader personality, and cultural intelligence (CQ). In doing so, I attempt to identify research-informed theory and practices that may inform how organizations incorporate virtual teams into their business operations and how they select and train leaders who can manage GVTs effectively. Previous scholars have attempted to answer parts of this question by addressing leadership in a wired world but few have focused on GVTs specifically and only a small number have worked to give a comprehensive view of all e-leadership requirements. For example, researchers have focused on establishing trust in virtual teams (Greenburg et al., 2007: Sarker et al., 2011). In other instances, GVT leader cultural intelligence is the only virtual team aspect that is investigated (Groves \& Feyerherm, 2011). The prevalence of research on virtual teams and global virtual teams is rapidly expanding and this research will give a necessary unification of the divergent literature on e-leadership.

This review is aimed at expanding organizational and leadership insights into the attributes, behaviors, personality characteristics, team building, and interpersonal skills that are a necessity of successful e-leaders of GVTs. Figure 1 reflects the findings of this research and may also serve as a conceptual guide for understanding how all the concepts of GVT leadership intersect to contribute to team effectiveness. This report offers a qualitative integration and synthesis of the available literature on the obstacles and opportunities that virtual work brings to an organization and strategies for hiring and training the best leader for the job. I will also point to specific gaps in available information on e-leadership, directions for future research and 
propose a new evaluation system for identifying leaders that would be ideal for virtual leadership.

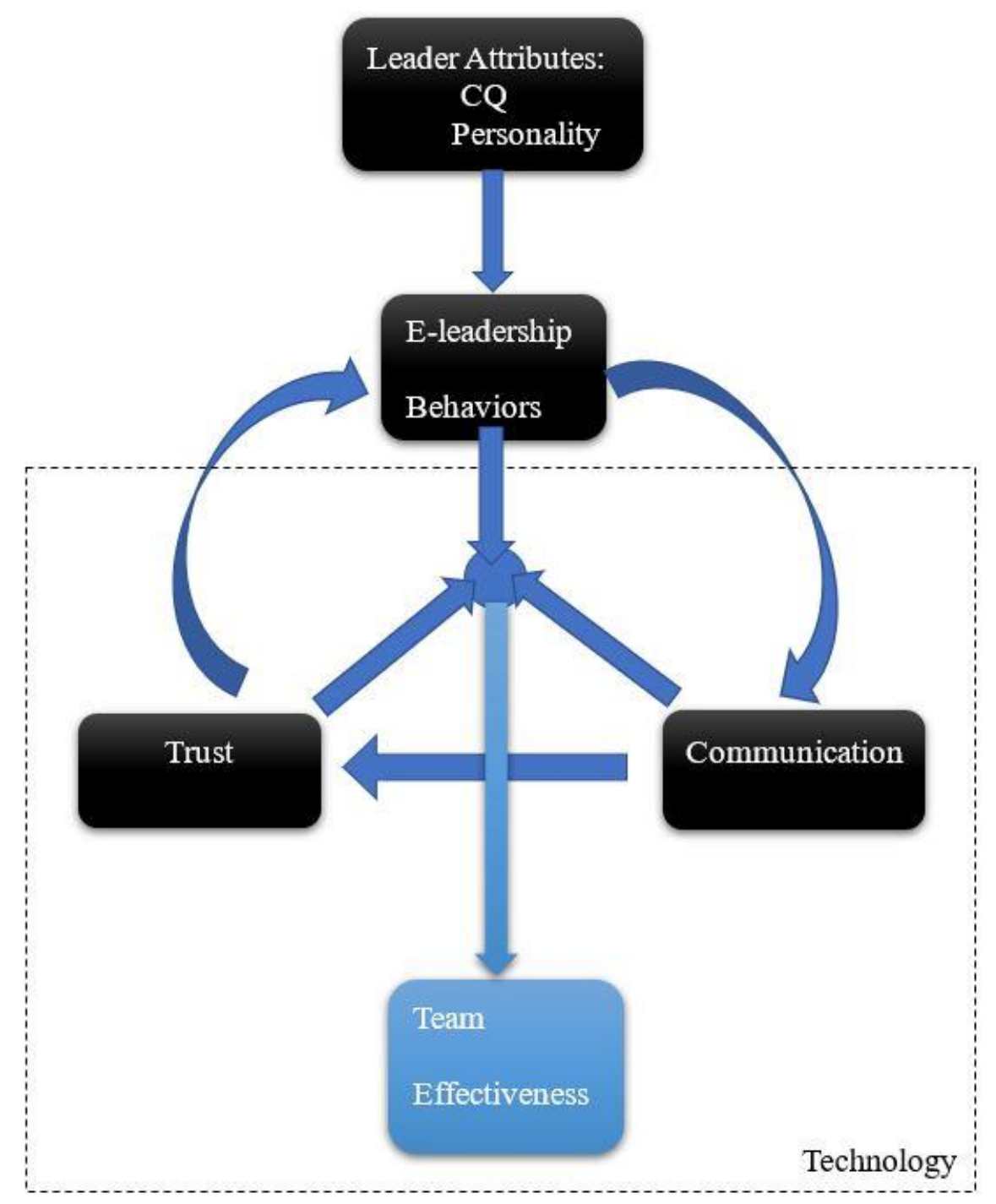

Figure 1. GVT Leader Concepts

\section{Literature Review Methods}

To conduct the literature search for this review, I used a keyword search with different combinations of the following terms: virtual leadership, virtual teams, e-leadership, e-teams, and global virtual teams (GVT). I began by searching for academic peer-reviewed sources. I used the following databases and resources to search for academic research and theory papers on the 
aforementioned topics: Google Scholar, Business Source Premier, and Business Expert Press Digital Library. Two research phases were used to identify the specific constructs that are essential to lead GVTs. The first phase was to only search for the topic of e-leadership in order to track what topics have been addressed most frequently in the literature on e-leadership. The following sections address the specific criteria used in these searches for the first stage of my analysis.

Inclusion criteria. After identifying an initial pool of articles, in the first stage of the review process, I conducted a thorough review of the articles pertaining to leading virtual teams. In this stage of the research, I used articles in my table to identify key constructs, and if they addressed leading virtual teams and identified multiple focus points in their articles. For example, articles such as Lillian (2014) were used in building the table because it addressed eleadership, communication, trust, diversity, and distance. Another aspect for inclusion is if alternative leadership styles/behaviors were comparatively analyzed for performance in leading virtual teams. I then categorized which unique characteristic(s) of e-leadership was/were identified in each article as essential and used those to narrow the topic into the most critical aspects of e-leadership. Additionally, I used these articles' reference lists to identify other potentially related articles. For the purpose of my review, I focused only on the findings and the identified attributes and behaviors that apply only to virtual teams and GVTs.

Exclusion criteria. To track what constructs of virtual leadership were brought up most frequently and their relevance to this paper, a few factors resulted in their removal from Table 1 but could still be used in the rest of the review. If the article only addressed one sept of virtual leadership, it was not included in the table because its purpose was not overall e-leadership but instead had relevance towards the development of only one e-leadership dimension. For 
example, Breuer, Huffmeier and Hertels (2016) meta-analysis investigated trust and its relation to team effectiveness in virtual teams so it was not included in building the e-leadership table but was used in the second stage of the analysis.

Table 1. Essential elements of Productive Virtual Teams

\begin{tabular}{|c|c|c|c|c|c|c|}
\hline \multicolumn{7}{|c|}{ Constructs Identified in E-Leadership } \\
\hline Source & Trust & CQ & Leadership Style & $\begin{array}{l}\text { Commu } \\
\text { nication }\end{array}$ & $\begin{array}{l}\text { Techno } \\
\operatorname{logy}\end{array}$ & Miscellaneous \\
\hline $\begin{array}{l}\text { Anantatmula \& } \\
\text { Thomas (2010) }\end{array}$ & & $\mathrm{X}$ & Not Specified & & & $\begin{array}{l}\text { Global Bus. } \\
\text { Environment }\end{array}$ \\
\hline $\begin{array}{l}\text { Andressen et al., } \\
(2012)\end{array}$ & & & Transformational/Self & & & $\begin{array}{l}\text { Motivation/Virt } \\
\text { uality }\end{array}$ \\
\hline $\begin{array}{l}\text { Balthazard, Waldman } \\
\text { \& Warren (2009) }\end{array}$ & & & Transformational & & & \\
\hline $\begin{array}{l}\text { Bell \& Kozlowski } \\
(2002)\end{array}$ & & $\mathrm{X}$ & Self-Managing & $\mathrm{X}$ & $\mathrm{X}$ & $\begin{array}{l}\text { Development } \\
\text { functions }\end{array}$ \\
\hline $\begin{array}{l}\text { Cascio \& Shurygailo } \\
(2003)\end{array}$ & $X$ & $\mathrm{X}$ & Not Specified & $\mathrm{X}$ & $X$ & \\
\hline Chang and Lee (2013) & & & Transformational & & & $\begin{array}{l}\text { Managing } \\
\text { Conflict }\end{array}$ \\
\hline Dennis et al. (2013) & & $\mathrm{X}$ & Not Specified & $\mathrm{X}$ & & Team Building \\
\hline DeRosa (2011) & $\mathrm{X}$ & & Not Specified & $\mathrm{X}$ & $\mathrm{X}$ & Training \\
\hline Derven (2016) & & & Inclusive & & $\mathrm{X}$ & $\begin{array}{l}\text { Diversity, } \\
\text { Inclusion, } \\
\text { Conflict MGMT }\end{array}$ \\
\hline $\begin{array}{l}\text { Eseryel, Y. \& Eseryel, } \\
\text { D. (2013) }\end{array}$ & & & Transformational & & $\mathrm{X}$ & $\begin{array}{l}\text { Action- } \\
\text { Embedded }\end{array}$ \\
\hline $\begin{array}{l}\text { Gajendran \& Joshi } \\
\text { (2012) }\end{array}$ & & & LMX & $\mathrm{X}$ & & \\
\hline Hambley et al., (2007) & & & Not Specified & $\mathrm{X}$ & $\mathrm{X}$ & $\begin{array}{l}\text { Work } \\
\text { Personalization }\end{array}$ \\
\hline $\begin{array}{l}\text { Hoch \& Kozlowski } \\
\text { (2014) }\end{array}$ & & & $\begin{array}{l}\text { shared team } \\
\text { leadership }\end{array}$ & & & $\begin{array}{l}\text { Structural } \\
\text { Supports }\end{array}$ \\
\hline $\begin{array}{l}\text { Hajro \& Pudelko } \\
(2010)\end{array}$ & & $\mathrm{X}$ & $\begin{array}{l}\text { Inspiration \& } \\
\text { Motivational (T) }\end{array}$ & & & $\begin{array}{l}\text { Knowledge } \\
\text { Transfer }\end{array}$ \\
\hline Hosseini et al., (2013) & $\mathrm{X}$ & $\mathrm{X}$ & Holistic approach & $\mathrm{X}$ & $\mathrm{X}$ & \\
\hline Huang et al., (2010) & & & Transactional \& & & & \\
\hline
\end{tabular}




\begin{tabular}{|c|c|c|c|c|c|c|}
\hline & & & transformational & & & \\
\hline Iorio \& Taylor (2015) & & & $\begin{array}{l}\text { Transactional \& } \\
\text { transformational }\end{array}$ & $X$ & $X$ & $\begin{array}{l}\text { GVT experience } \\
\& \text { cross- } \\
\text { generational } \\
\text { teams }\end{array}$ \\
\hline $\begin{array}{l}\text { Lee-Kelley \& Sankey } \\
(2008)\end{array}$ & $\mathrm{X}$ & $\mathrm{X}$ & Not Specified & $\mathrm{X}$ & & \\
\hline $\begin{array}{l}\text { Lauring \& Jonasson } \\
(2018)\end{array}$ & $X$ & $X$ & $\begin{array}{l}\text { Inspiration \& } \\
\text { Motivational (T) }\end{array}$ & $\mathrm{X}$ & & \\
\hline Liao (2017) & $X$ & & $\begin{array}{l}\text { Multi-Level, LMX, } \\
\text { Transformational \& } \\
\text { Transactional }\end{array}$ & & $X$ & All 3 styles \\
\hline Lillian (2014) & $X$ & $\mathrm{X}$ & $\begin{array}{l}\text { Inspiration \& } \\
\text { Motivational (T) }\end{array}$ & $\mathrm{X}$ & & $\begin{array}{l}\text { Distance \& } \\
\text { Time }\end{array}$ \\
\hline Maduka et al., (2018) & $\mathrm{X}$ & & Transformational & $\mathrm{X}$ & $\mathrm{X}$ & $\begin{array}{l}\text { task clarity, } \\
\text { personality }\end{array}$ \\
\hline $\begin{array}{l}\text { Poulson \& Ispen } \\
(2017)\end{array}$ & $X$ & & Not Specified & & & $\begin{array}{l}\text { Working } \\
\text { conditions }\end{array}$ \\
\hline $\begin{array}{l}\text { Purvanova \& Bono } \\
(2009)\end{array}$ & & & Transformational & & & \\
\hline
\end{tabular}

As shown in Table 1, there has been an extensive investigation into what are the most important factors of leading a virtual team. Of those identified the ones that emerge most frequently are trust, transformational leadership or a sub-dimension of transformational leadership indicated with (T), cultural intelligence (CQ), communication, and technology. Based on the findings in Table 1, the second stage involved searching for articles on each construct identified to understand their relevance, definitions, and strategies as they pertain to e-leadership. These factors do not function independently of each other but are intersectional and can serve to enhance or inhibit GVT performance. All of the factors identified will be fully explored by defining these concepts in regards to virtuality and their importance, as well as strategies for eleaders. The topic of communication, while it is brought up substantially in the extant literature on virtual teams, it is standardly tied to another aspect of e-leadership. It is for this reason that 
this review will address communication as a subset to trust, e-leadership behaviors, cultural intelligence, and technology.

\section{Trust}

Trust is brought up most frequently as an imperative to leading a virtual team. Similar to F2F teams, trust affects the performance of all teams and has been established as vital to meet team and organizational objectives. Trust is addressed as: trust in leader, trust between members, and their composite, team trust. Previous research shows that trust is an increasingly more prominent indicator of virtual teams' objective achievements and success (Germain, 2011). Trust not only has an impact on the overall performance of the team but can also serve as a predictor of the performance of team members at the individual level (Sarker, S., Ahuja, M., Sarker, S., \& Kirby, 2011). When it comes to building trust in a F2F team, F2F interactions is an important step in gaining team members trust (Dennis, Meola \& Hall, 2013). An initial meeting is not feasible for all GVTs due to time or budget constraints and this lack of initial interpersonal interaction can serve to inhibit trust. Many articles on virtual team effectiveness stress that even just one F2F meeting in the initial stages of the team can greatly benefit team members trust, knowledge sharing and team productivity (Dennis et al., 2013; Kuruppuarachchi, 2009; Marlow, Lacerenza, \& Salas, 2017; Vayrynen \& Alto, 2013).

\section{Definition of Trust}

The most frequently cited definition of trust used in virtual team research is "the willingness of a party to be vulnerable to the actions of another party based on the expectation that the other will perform a particular action important to the truster, irrespective of the ability to monitor or control the other party" (Mayer, Davis, \& Schoorman, 1995, pg. 712; Guinaliu \& Jordan, 2015; Sarker, Ahuja, \& Kirkeby, 2011; Ford, R., Piccolo, \& Ford, L., 2017; Bruer, 
Huffmeier, \& Hertel, 2016; Choi, \& Cho, 2019). In Guinaliu and Jordan's (2016) study, they adapted the definition of trust to characterize the members' trust in a leader as, "the expectation or belief that one can rely on the words and actions of the leader and that the leader will have good intentions for the team at all times" (p.60). Both of these definitions indicate that leaders need to focus on developing trust personally with their staff, between the individual members and work towards the establishment of "team trust" (Breuer, Hertel, \& Huffmeier, 2016). Team trust may be conceptualized as the summation of the individual experiences of the team members into a concentration of shared impressions, and perspectives (De Jong \& Elfring, 2010; Breuer et al., 2016).

\section{Importance of Trust in GVTs}

Trust has the ability to affect multiple aspects of a team's processes, and it can hinder participation, collaboration, contribution, innovation, product quality, and team member retention (Breuer et al., 2016; Choi \& Cho, 2019; Coovert, Miller \& Bennett, 2017; Germain, 2011; Greenburg, P., Greenburg, R., \& Antonucci, 2007; Guinaliu \& Jordan, 2016; Sarker et al., 2011). Establishing trust in virtual teams is essential because of the potential benefits it can have on the organization. In a study by Breuer, Huffmeier, and Hertal (2016), trust was more strongly associated with team performance in virtual teams as compared to F2F teams. Trust has been shown to positively affect team-related attitudes, information processing, coordination, and cooperation between members, as well as, knowledge sharing, and team learning (Breuer et al., 2016). High levels of trust in virtual teams can inspire a spirit of cooperation and information exchange despite team diversity (Curseu, \& Schruijer, 2010). Evidence shows that virtual teams have more difficulty developing trust due to the technology-mediated communications, but there are some procedures that can lessen this effect (Greenburg et al.,2007; Ferrell \& Kline, 2018). 
Previous research has identified strategies on how an e-leader can develop trust within a virtual team.

Even with modern technological advances such as Google Hangouts/Meet and video conferencing, trust is difficult to develop because virtual teams do not have the same social amplitude of traditional teams (Greenberg, et al., 2007). In F2F team meetings, people have the ability to see each other's nonverbal communications such as body language, facial expressions, and social cues that make F2F have higher social amplitude than GVTs. The lack of physical interaction in GVTs lessons the amount of information members can glean from their interactions. Virtual teams are recognized to have a higher degree of uncertainty due to the nature of their operations; trust can serve to reduce this level but is also more challenging to build because of the technologically-enabled communication style (Coovert, et al., 2017; Germain, 2011). Virtual work also has an effect on the perception of the team members and they can easily feel that because they do not work within the organization's offices that they will be forgotten (Ford, et al., 2017).

Aspects of virtual teams can also handicap team processes. Often virtual teams are assembled for the purpose of a single project and this can alter the attitudes of team members (Sarker et al, 2011). Elements like this can cause fear of work exploitation of team members and make trust a critical component of team success (Sarker, et al., 2011). The task of the virtual leader is to break down the barriers to trust through the use of strategies that have been shown to be effective in previous studies. The trust barriers they will need to consider are individual, teambased, organizational, and technological (Germain \& McGuire, 2014). Team based barriers can include; lack of social interaction, cultural differences, and deficient direction from leadership (Germain \& McGuire, 2014). Individual barriers are aspects such as unwillingness to participate 
in information sharing with team members or lack of connection to the team (Germain \& McGuire, 2014). Examples of technological barriers - which will be discussed in a later section - are media richness, complexity or individual knowledge of the tools being utilized and lack of instantaneous communication (Germain \& McGuire, 2014). Organizational barriers are when there is a lack of formal structures outlined for the virtual team (Germain \& McGuire, 2014).

\section{Trust and Communication}

Trust and communication have been shown to influence individual performance (Ferrel \& Kline, 2018; Sarker, et al., 2011). In GVTs there has been found that too much communication can have a significant negative impact on the perceived performance of the overly communicative individual, but this situation appears to most problematic when individuals that have not gained the trust of the team (Chang, Hung \& Hsieh, 2014; Sarker, et al. 2011). If an individual has developed trust, research has shown that the opposite effect occurs, and their communicativeness is seen as positive and productive (Sarker, et al., 2011). Communication standards are important to the development of trust in GVTs, and there is such a thing as too much communication (Greenburg et al., 2007; Sarker, et al., 2011; Verberg, Bosch-Sijtsema \& Vartiainen, 2013). This is why it is crucial that e-leaders establish communication norms at the beginning stages of the team project (Edison, 2011; Greenburg et al., 2007; Marlow et al, 2017; Sarker et al., 2011).

The applicability and necessity of communications are more important than sending abundant communications, and the e-leader should ensure that team members are sending emails that are applicable to the recipient (Verberg et al., 2013). In order to effectively lead a diverse GVT, leaders need to be apparent when communicating the duties of members to circumvent confusion (Greenberg et al., 2007). In a literature review of the research on virtual teams by 
Marlow, Lacernza, and Salas (2017), the authors found that the communication norms that leaders establish should place emphasis on the acknowledgment of team members, frequency, and response quality. To maintain trust throughout the duration of the team it is important to consider the timeliness of responses and, if a member is going to be absent, to inform team members ahead of time, as these strategies may mitigate trust minimization (Marlow, et al., 2017).

It is also important to take into consideration the factors of misinterpretation or miscommunication; this is why trust is so pivotal to GVTs. For example, a misinterpreted email can often go without response if trust is low (Chang et al., 2014; Marlow et al., 2017). Allowing situations like these to go unchecked can be detrimental to the team's function because it may hinder information sharing, which is central to GVT performance (Marlow et al., 2017). In another study, it was found that team-based rewards served to increase communication among team members in virtual teams (Rack, Ellwart, Hertel, \& Konradt, 2010).

\section{Trust Development Strategies}

The beginning phase of a virtual team is a decisive time for the development of trust (Germain \& McGuire, 2014). After all team members are identified it is necessary for the leader to take steps to begin building the relationships amongst the team members. Before work begins, introductions of the team members - which includes their qualifications, endorsement by the team leader, background information, personal work style, and their role within the team - must be held (Ford et al., 2017; Greenburg et al., 2007). In this phase, Greenburg (2007) also suggested a team building strategy whereby the members conducted interviews with each other to learn each other's background and then presented their interviewee to the rest of the team. This initial meeting has the potential to build rapport and set the team up for open 
communication and knowledge sharing (Ferrell \& Kline, 2018). Another construct to trust is that the leader needs to clarify the reason behind the team's formation and define the team goals (Eidson, 2011). This step is necessary so that the team members grasp the objective of their work and how it fits in with the organization's goals (Eidson, 2011).

In the developmental stages, it is also imperative that the leader sets guidelines for behavioral norms such as responsiveness, reliability, and consistent follow-through (Peters \& Karen, 2009; Germain, 2011). Strategies such as sharing of group goals and openness of organizational activities can aid in the early establishment of a collective identity (Germain, 2011; Ford et al., 2017). In previous research, the installation of these two trust strategies is referred to as swift trust (Germain, 2011). These studies have shown that gaining swift trust in a virtual team will enhance their performance and quick-start the communication and information sharing processes among team members (Germain, 2011; Germain \& McGuire, 2014; Ferrell \& Kline, 2018). In order for trust to swiftly develop in virtual teams, members may need more time and encouragement from leadership to engage in social communication prior to the onset of work activities (Germain \& McGuire, 2014). By building these social connections first, it will aid the team's development of shared norms and values, which is especially important in the absence of previous work exchanges (Germain \& McGuire, 2014). By using activities such as online team building, and customization of tasks for individual employees, trust can emerge (Germain, 2011). Online team building activities should be organized in such a way that it requires members to share past experiences and personal values (Ferrell \& Kline, 2018; Germain, 2011).

Training on how to be a virtual employee can be useful even to those that have previously worked in this environment. This training should address multiple characteristics of virtual work that employees will encounter (Greenburg et al. 2007; Ford et al. 2017). Recognition of the 
unique challenges that employees might face while working in a virtual team. Technical training on the platform used at the organization, as well as recognizing that team members might experience technical challenges that may inhibit communication (Greenburg et al., 2011). At times, there might be a communication lag due to technical issues, and this can be misinterpreted as a disengaged or un-participative member. It is important that there is a strategy set in place for these situations to prevent loss of trust (Greenburg et al., 2011).

Trust is a dynamic concept in virtual teams and needs to be managed throughout the entirety of the team's duration (Coovert et al., 2017). Monitoring of the team during the period of the team's project(s) is a part of the e-leadership strategy. As with any team setting, there are common problems that may develop over the life of the team. These need to be checked by the team leader, F2F teams often have innocuous joking and kidding between members of the team. In the virtual setting, these can easily be misinterpreted and create conflict between members and damage the team's trust, and should be discouraged by the e-leader (Greenburg et al., 2011). In addition, leaders should be on the lookout for the growth of unofficial subgroups, as these can create tension by individuals being left out of work knowledge and information sharing (Greenburg et al., 2011). Keeping track of communication frequency to ensure that all members are responding swiftly to their counterparts and encourage non-task related communication (Ford et al., 2017; Greenburg et al., 2011). Trust in virtual teams can be negatively impacted by a lack of communication frequency or silence of a member (Sarker et al., 2011). One study found an organization that employed a virtual break room tool, which was used for communication between employees and when someone entered the break room other members received a notification (Ford et al., 2017). This strategy shows employees that the organization is taking steps to try and outweigh the isolation of virtual employees and conveys a message of caring 
(Ford et al., 2017). Automated recording of team interactions online can serve to increase trust because it lessens the perceived risks from team members slacking or freeriding (Breuer et al., 2016).

The reward structure is an important element of team trust towards its development and its maintenance. Some research on virtual teams has found that prevalent methods used in F2F environments such as competitive rewards will be damaging to a virtual team (Edison, 2011; Germain, 2011; Greenburg et al., 2007). The results of using competitive rewards in a virtual team can prove disastrous, as they have been found to negatively impact the perception of team members motives, information sharing, and their ability to work together towards common goals (Edison, 2011; Greenburg et al., 2011). Instead, the use of cooperative rewards has been found to be powerful at maintaining a positive team climate of trust (Ford et al., 2017; Germain, 2011; Polzer, Crisp, Jarvenpaa \& Kim, 2006). Cooperative and team-based awards are given based on the performance of the team as a whole. Studies have shown that in a virtual environment this is the best method in order to maintain trust and communication between team members (Rack, et al., 2010). Another aspect of reward structure that needs to be taken into consideration is individual recognition to the team effort. Even though the reward should be disseminated equally to the members, research suggests that leaders do a virtual award ceremony where individual achievements and contributions to the team are recognized (Greenburg et al., 2011).

\section{Table 2. Trust Strategies}

\begin{tabular}{|c|c|}
\hline \multicolumn{2}{|r|}{ Trust } \\
\hline \multirow[t]{2}{*}{ Beginning Strategies } & $\begin{array}{l}\text { Introduce team members through a video } \\
\text { conference, including; qualifications, give an } \\
\text { endorsement, background information, personal } \\
\text { work style and their role in the team }\end{array}$ \\
\hline & OR \\
\hline
\end{tabular}




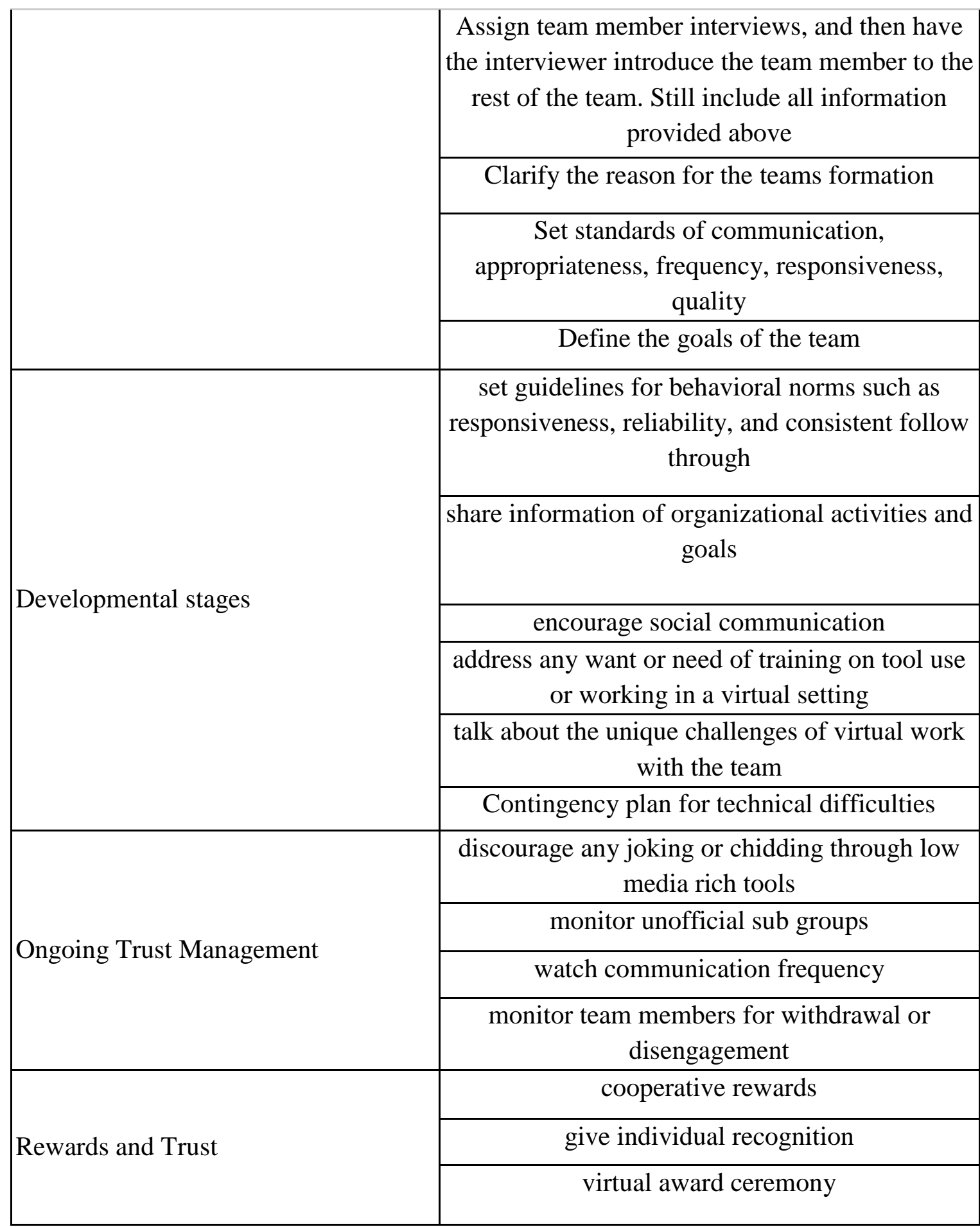

Source. Adapted from Germain (2011), with added contextual information from: Coovert, Miller and Bennett (2017); Edison (2011); Ferrell \& Kline (2018); Ford et al. (2017); Germain and McGuire (2014); Greenburg et al. (2011); Guinaliu and Jordan (2016); Peters and Karen (2009); Polzer (2006). 


\section{Leadership Behaviors and Styles}

With regard to leadership behaviors for virtual leadership there is still disagreement as to which style (i.e., set of behaviors) is most effective, and often the literature does not address which style is being investigated. In the instances in which the research does identify leadership style, transformational leadership or its sub-dimensions are most frequently identified as the model when considering the factor of virtuality. Out of the first phase of literature analyzed that identified leadership methodology as a key construct to virtual team success, nine identified transformational leadership as successful, three identified inspirational motivation (a dimension of transformational leadership), and one identified people-oriented (which it conceptualized as transformational and servant leadership) as critical to the performance of the team. These account for approximately three quarters of virtual team articles that addressed leadership style and over half of all reviewed articles. In the literature reviewed for this paper, there was also a significant number of articles that did not definitely classify the behaviors and actions exhibited by successful e-leaders to an established leadership style. Of the literature reviewed one third fall into this category. This review will attempt to encompass both transformational leadership style, and will also consider the behaviors and actions that have been singled out in other research as rewarding into the various established leadership styles. Although the methods of e-leadership are still in a debate the one thing there is a consensus on is that the leadership role is an integral component in virtual teams. As indicated by Hajaro and Pudelko (2010), in a study consisting of 70 interviews of people working in global multicultural teams, the respondents identified leadership as critical to the performance of the teams.

There has been some agreement in research that confirms transformational leadership behaviors as effective in leading GVTs but disagrees that this alone is the primary method for e- 
leadership. In Hambley, O’Neill, and Klien's (2007) qualitative study of e-teams, they identified behaviors used by effectual leaders and they noted that while most could be part of transformational leadership, not all behaviors or skills were suitable for the transformational leadership framework. Hosseini, Zou, Chileshe, and Baroudi (2013) proposed that in previous research there has been a variety of methods introduced as effective in virtual teams, but what they all have in common is that they take into account the unique challenges faced by team members. This indicates that there may be varying levels of success, but as long as the e-leader is focused on each individual, including their culture and the effect of communications through technology they can lead e-teams effectively (Hosseini et al., 2013).

Multiple studies indicated that certain beneficial leader actions included leader-member exchange (LMX), transformational, or transactional leadership, and those too will be addressed in this section (Gajendran \& Joshi, 2012; Hambley et al., 2007; Huang et al., 2010; Liao, 2017). Logical interpretation leads to the deduction that a single style does not universally supplant all other styles when it comes to managing virtual teams. It is important to note that LMX behaviors and actions involve transactional and transformational leadership behaviors because it uses an exchange-based approach and social-exchange approach to leadership (Graen \& Uhi-Bien, 1995). This is why some researchers have argued for a multi-level leadership perspective because these three styles all play a role in leading GVTs (Huang et al., 2010; Liao, 2017; Zander, Mockaitis \& Butler, 2012). Because GVTs are made possible through the advancement of technology, it is also important to point out that actions and behaviors that are created by these technologies will not necessarily fit into these established styles.

\section{Transformational Leadership}


The argument for transformational leadership and its subdimensions is compelling because its unique characteristics are well suited for overcoming some of the difficulties faced by GVT members. Transformational leaders display unique characteristics that engage, relate to, and encourage their followers. Members of GVTs often primarily work in a setting that is absent of consistent and direct F2F interpersonal interaction, and thus a leader must be able to surmount the feelings of isolation often experienced in this type of work. This is perhaps why the literature on GVTs largely focuses on this leadership style more than others.

Defining transformational leadership. The concept of transformational leadership was first theorized by Burns (1978) and Bass (1985) and it can be characterized as a substantial and prolific relationship between leaders and their team members to push the goal-oriented advance of the members. The research generally is in agreement that four main dimensions of transformational leadership exist, which were introduced by Bass and colleagues (1985): idealized influence, inspirational motivation, individualized consideration, and intellectual consideration. Idealized influence is accomplished by being the model for employees to emulate and the leader demonstrates qualities and values that they want to see in their team (Bass, 1985). Inspirational motivation is the ability to motivate and inspire employees by way of possessing and displaying a vision (Bass, 1985). Individualized consideration behaviors involve showing authentic interest in employee's needs, thoughts, and feelings to aid them in achieving goals (Bass, 1985). Intellectual stimulation is characterized through the encouragement of employees to challenge the processes and to be creative and innovative (Bass, 1985). It is easy to see how transformational behaviors lend themselves to overcoming the obstacles faced by team members on virtual teams, and of note, the individualized consideration is essential in addressing the 
feelings of isolation experienced by virtual workers. Leaders that act as role models and show idealized influence can also make it easier for staff to develop trust (Bass, 1985).

In a recent exploratory survey by Maduka, Edwards, Greenwood, Osborne, and Babatunde (2017) on the required competencies for leading a virtual team, the authors concluded that organizations should use transformational leadership attributes in their selection requirements if they desire high-performing teams. In Purvanova and Bono's (2009) experimental study on leadership methodology and its effects on team performance in F2F and virtual teams, the authors found that transformational leadership had a significantly stronger impact on team performance in virtual teams than in F2F teams and they hypothesized from these results are the result of technology-dependent communications. They also found those team members that reported more transformational leadership behaviors reported higher satisfaction with the team as well. Additional research indicates that when a virtual team project is more dynamic in nature transformational leadership can overcome technical difficulties and challenges that are unique to working in a GVT (Huang, Hahai \& Jestice, 2010). They confirmed previous research that transformational leadership is effective for situations where coordinating work and building relationships is problematic i.e., (Joshi et al., 2009) and that it will aid in building task cohesion (Huang et al., 2010). Huang's (2010) study also built on the results found in Purvanova and Bono's (2009) experimental study. In multicultural geographically dispersed teams Joshi, Lazarova, and Liao (2009) found that inspirational leaders were successful in creating a shared team identity and the members had a more positive perception of their leader and that they had greater engagement with the team and team trust.

Transformational leadership strategies. Because so much attention has been given to the capability of transformational leaders on virtual team productivity it is worthwhile to identify 
which transformational strategies leaders should capitalize. The groundwork for which behaviors and actions are correlated to each of the four transformational subdimensions has already been laid out by the multifactor leadership questionnaires of Bass, Avolio, and Jung (1999) and Avolio and Bass (2004). Other scholars have built off their theories and expanded the knowledge of the behaviors of transformational leaders by conducting surveys specifically targeted at virtual settings.

Idealized influence. As a reminder, when instilling idealized influence, transformational leaders act in such a way that their followers will want to emulate (Bass \& Avolio, 1994). The effectiveness of these behaviors is predicated on the degree to which a leader is respected, admired, and trusted by their followers (Bass \& Avolio, 1994). The path to accomplishing this is done by putting the team members before self-interests (Andresson et al., 2012; Bass \& Avolio, 1994). In one study by U. Y. Eseryel and D. Eseryel (2013), the authors explicitly designed their study to address a shortage in e-leadership - namely, while studies show that transformational leadership is effective in virtual teams, it previously did not address how e-leaders use these skills to influence team actions and performance. From an in-depth analysis of 25 team members in software development teams, the authors were able to determine which actions people take that demonstrate transformational leadership. They found that transformational leaders actively used role modeling to achieve their team's vision (Eseryel, U. Y., \& Eseryel, D., 2013). A few examples of role modeling are simple actions such as showing team members how to correct mistakes or displaying the appropriate methods to accomplish a task and willingly doing the same work that is asked of members of the team (Eseryel, U. Y., \& Eseryel, D., 2013). It is important for e-leaders to take actions that are outside of the realm of their self-interest for the benefit of the team and speak freely about what they value most (Andresson, et al., 2012). 
Inspirational motivation. Inspirational leadership methods have been found favorable for the development of trust and commitment in e-teams (Joshi et al., 2009). In some cases, inspirational motivation has been studied as a key indicator of leadership in virtual team performance (Joshi et al., 2009; Lauring \& Jonasson, 2016; Lillian, 2014). In Lauring and Jonasson's (2016) study on 23 GVTs, the authors found that goal setting with inspirational motivation leadership had positive group outcomes such as creating inclusive team member attitudes. Inclusive team member attitude is the knowledge and acceptance of other members dissimilarities and similarities (Lauring \& Jonasson, 2016). The behaviors used as indicators included: "My leader gets the team excited about the team's tasks;" "My leader is supportive of me sharing opinions and ideas;" I am inspired by my leader;" "My leader communicates his/her mission with me;" "My leader motivates the team to work together with his/her vision of what me can achieve together;" and "My leader instills a notion that we can overcome any challenge with teamwork."

Inspirational motivation behaviors are also reflected in taking actions such as communicating confidence that team objectives can be reached and talking with enthusiasm about tasks that need to be achieved (Balthazard et al., 2009). Team leaders should also be able to communicate excitement about the team's future (Andresson, et al., 2012). Overall, inspirational leadership is about acting in a manner that inspires the members of the team by bringing challenge and meaning to the task at hand (Bass \& Avolio, 1994).

Individualized consideration. Leaders should recognize followers' individual differences, including their skills, knowledge, abilities and cultural values (Bass \& Avolio, 1994). GVTs are usually built based on the difference of individual knowledge, skills, and abilities of its members to be an efficient team, and it is important that the e-leader is able to 
recognize each individual's unique capabilities to capitalize on their contributions (Bass \& Avolio, 1994). Individualized consideration goes beyond the individual's job description, eleaders need to have the aptitude to recognize personality differences such as a preference for structured work, more autonomy, and increased engagement (Bass \& Avolio, 1994). In Guinaliu and Jordan's (2015) study, they discovered that when employees are more willing to trust leaders that are perceived to show them empathy, which is a key behavior of individualized consideration (Bass, 1985). e-leaders should be able to recognize individual member strengths and support the member in their development (Andresson, et al., 2012). A way to develop this rapport with employees e-leader should conduct one-on-ones with the members and, if possible, arrange for F2F interactions (Hambley et al. 2007).

Intellectual stimulation. The final dimension of transformational leadership, can be displayed using behaviors such as seeking out multiple perspectives when looking for solutions to a team problem, questioning team assumptions to determine if they are applicable and trying new approaches to encourage team members innovation and creativity (Balthazard et al., 2009; Bass \& Avolio, 1994). Furthermore, research on virtual team leaders revealed that subject matter experts were identified as action-embedded transformational leaders because they used their superior knowledge to assist others to solve problems with innovative or enhanced solutions (Eseryel, U. Y., \& Eseryel, D., 2013). A part of intellectual stimulation is making sure that as a leader there is no discouragement of team members sharing ideas, the critique of mistakes should be conducted only in a private and constructive method (Bass \& Avolio, 1994).

\section{Transactional Leadership}

Certain aspects of transactional leadership have been isolated as needed for the leadership of virtual teams (Dennis, Meola \& Hall, 2013; Hambley et al, 2007; Huang, et al., 2010; 
Kuruppuarachchi, 2009; Liao, 2017). This leadership approach is characterized by giving rewards based off of employee performance and active or passive management by exception. The first aspect, contingent rewards, involves informing the employee of what their expectations are and setting those performance goals. The transactional leader does not seek innovation or change; rather, they put clear guidelines for their employees, structure, organization and adhere to established company policies and culture. Leaders of virtual teams should use a few transactional behaviors in order to be effective at goal setting and setting individual expectations, and assigning roles within the team are frequently addressed in GVT literature (Dennis et al., 2013; DeRosa, 2011; Germain, 2011; Hajaro \& Pudelko, 2010; Hambley et al., 2007; Kuruppuarachchi, 2009).

GVT members rely on the leader and each other in order to accomplish goals and the distance between them make role and goal setting critical for each member to do their job. Active management by exception is where leaders seek out and take action when employees make mistakes or diverge from the norm. Certain studies have found that in GVTs it is necessary to monitor the team for any problems early, the establishment of unauthorized subgroups and deviation from the team's culture (Greenburg et al., 2011; Hjaro \& Puldelko, 2010; Kuruppuarachchi, 2009). The passive management by exception of transactional leadership is not a style that would be effective in a virtual setting. GVT members need to work together to accomplish the goals and a leader that only shows up to correct mistakes would likely be detrimental to the trust and performance of the team. Comparative analysis between transactional and transformational leadership on GVT performance has indicated that transformational leadership is more effective in GVTs for attaining a cooperative team climate, but certain aspects of transactional leadership are valuable in managing a virtual team (Huang, Kahai \& Jestice, 
2010). In Huang, Kahai, and Jestice's (2010) study of virtual team collaboration, the authors found that when virtual teams were characterized by low media richness, the use of transactional leadership had a stronger effect on team task cohesion. In this scenario, leaders clarified the reward scale to the team and they used a conditional reward to incentivize employees to get the job completed (Huang et al., 2010).

\section{Leader-Member Exchange (LMX)}

This leadership style is often referred to as the relationship-based approach (Graen \& Uhl-Bien, 1995). It is easy to see how this approach could be useful to virtual leadership, as it requires that the leader has a relationship with each member that is cognizant of their personalities and culture and LMX focuses on the differentiated dyadic relationships that develop. Many of the strategies for transformational and transactional leadership are also forms of the LMX relationship. Multiple studies have pointed towards this element of e-leadership and recommend that e-leaders should use an approach that encompasses certain aspects of these three leadership styles (DeRosa, 2011; Hambley et al, 2007; Liao, 2017). Another study by Gajedran and Joshi (2012) identified certain aspects of LMX as effective towards increasing member involvement and inclusivity. The findings suggest that developing dyadic relationships with team members will increase member impact on team decisions and the aggregate of these relationships will result in increased creativity and innovation (Gajendran \& Joshi, 2012). The relationships of followers of LMX leaders are described as having mutual trust, respect, and a sense of obligation to the leader (Graen \& Uhl-Bien, 1995). A significant amount of the literature that did not identify an established leadership style listed actions and behaviors that can be classified as LMX such as active listening of individual members, recognition of individual differences, 
maintenance of trust and relationships, having one-on-one meetings, and seeking each members input (DeRosa, 2011; Germain, 2011; Hambley et al., 2007; Kuruppuarachchi, 2009).

\section{Communication and Leadership}

Leaders of virtual teams need to have strong communication skills and the aforementioned leadership styles are predicated on effective and timely communication. That is, communication is the key to all of the strategies that have been outlined in the trust and leadership strategies. Accordingly, the importance of regular communication between all members and the e-leader cannot be understated. Routine communication is fundamental when team building, it gives team members a chance to contribute ideas, and it will foster team inclusivity (Eidson, 2011). It is the e-leaders role to encourage the team to communicate with each other and to set the boundaries to discourage any miscommunication (Daim, Ha, Reutiman, Hughes, Pathak, Bynum \& Bhatla, 2010). GVTs are characterized as being highly interdependent for information, personal knowledge, and skills. Utilizing social activities that encourages and motivates the team to engage in collective and regular communication can increase team cohesion and could build organizational value creation and team achievement (Lillian, 2014).

\section{Trust and Leadership}

Leaders play an essential role in developing trust with their members and they must aid in facilitating trust between GVT members. Trust in the leader is important to establishing a relationship where members are more commitment and support of the leader's decisions (Guinaliu \& Jordan, 2016). In order to gain the trust of their follower's, e-leaders need to be empathic to members by listening and understanding their feelings (Guinaliu \& Jordan, 2016). It has been recognized that in order for teams to have regular communication and knowledge sharing building team trust is key (Ferrell \& Kline, 2018). As stated in the trust strategies (see 
Table 2) leaders need to foster trust and communication by performing an initial introduction of each of the members or have members introduce each other prior to being work processes (Ferrell \& Kline, 2018; Ford et al., 2017; Greenburg et al., 2007). During this introduction, the eleader can inform members of each other qualifications, backgrounds, and roles within the team to establish their competencies to each member (Ford et al., 2017; Greenburg et al., 2007). Activities that encourage communications amongst team members such as these will help build rapport and trust between members (Ferrell \& Kline, 2018; Ford et al., 2017; Greenburg et al., 2007).

\section{Cultural Intelligence}

GVTs offer an opportunity for organizations, they give exclusive access to the local needs and leverage of cultural diversity, but in order to gain these advantages, their global teams need to be effective (Mockaitis et al., 2018). The 2016 virtual teams survey report brought to light how dire the need is for better cultural intelligence (CQ) for team efficacy. It found that $98 \%$ of GVT leaders reported satisfaction with their intercultural leadership skills but only $19 \%$ of their team members agreed that they had the skills necessary to lead a diverse team (RW3 CultureWizard, 2016). In terms of productivity, the survey found that $68 \%$ of respondents considered cultural challenges as their team's number one impediment (RW3 CultureWizard, 2016). These findings are backed by other research and leader cultural intelligence has been identified as crucial for team performance in the extant literature on GVT leadership (Anantatmula \& Thomas, 2010; Dennis et al., 2013; Henderson, Stackman \& Lindekilde, 2018; Moon, 2013; Presbitero \& Toledano, 2018).

\section{Definition of Cultural Intelligence}


CQ can be characterized as the competence of an individual to adjust adequately to an unfamiliar cultural context and the capability to lead people from diverse cultural backdrops (Ang \& Van Dyne, 2008; Erez, Lisak, Harush, Glikson, Nouri \& Shokef, 2013; Moon, 2013). The four-factor model of CQ is the most frequently used method of evaluation used to correlate CQ and performance in research on personality (Ang, Dyne \& Koh, 2006; Ismail, Reza \& Mahdi, 2012; Li, Mobley \& Kelly, 2016; Presbitero, 2016). The four factors are metacognitive CQ, cognitive CQ, motivational CQ, and behavioral CQ (Ang \& Dyne, 2008). Metacognitive CQ refers to a person's level of conscious cultural awareness while they are interacting in a crosscultural situation and their knowledge of that culture, enabling them to act accordingly to the others cultural standards. Cognitive CQ is the individual comprehension of their own cultural differences as well as knowledge of the norms, habits, and traditions of other cultures. The term motivational CQ is a reference to the personal aptitude and will to attain knowledge of how to be successful in cross-cultural interactions. The final component is behavioral CQ is the capability to display suitable demeanor verbally and non-verbally when interacting with different cultures.

\section{Importance of CQ for GVTs}

CQ is fundamental for managing GVTs which usually have a higher degree of diversity because team leaders need to have input from all individuals to achieve performance (Ang, and Van Dyne, 2008). Groves and Feyerherm's (2011) study showed that leader CQ is correlated with the perception of the leader's performance and to the team's performance. The findings in their study suggest that leaders that are high in CQ are more effective in managing diverse teams, they can identify the dynamics of their team and know which behaviors are appropriate for the situation (Ang \& Dyne, 2009; Groves and Feyerherm, 2011). These leaders will have the ability 
to manage their own cultural assumptions while developing an understanding of their team members culture and their individual needs (Groves \& Feyerman, 2011).

CQ can affect multiple facets of virtual work, including team member satisfaction, role clarity, trust, communication, and performance (Henderson, Stackman \& Lindekilde, 2018; Moon, 2013; Presbitero, 2016). It is imperative that the leaders of GVTs be high in CQ because they will shape the team's diversity environment perceptions (Rosenauer, Homan, Horstmeier \& Voelpel, 2016). Almost one quarter (23\%) of respondents in CultureWizards (2016) survey of GVTs, say their virtual teams fail to capitalize on their cultural diversity. The results of these surveys highlight the evidence that more attention needs to be given to the CQ of e-leaders. In Hajaro \& Pudelko (2010), the two aspects of the leader's competencies that were identified as pivotal were knowledge transfer and management and multicultural awareness. In their study, the 70 respondents on virtual teams identified that a leader's inability to manage culturally diverse followers as one of the most significant causes for project defeat.

\section{Effect of CQ on Team Communication}

GVTs are characterized by cultural diversity and it is important to recognize that individual backgrounds will influence communication behavior (Chang et al., 2014). Because of the various cultural backgrounds, media knowledge, and experience of the members, ways of expressing thoughts, wording, and thinking will differ amongst the team members (Chang et al, 2014). This is why it may be important to have a leader that has had exposure to cultural diversity and or has received cultural sensitivity training (Chang et al., 2014). Some research has shown that leaders that have good communication skills can alleviate the challenges of working in a diverse team even when the member's communication skill is not as considerable (Cummings, 2007). This study also suggested that when e-leaders work with multicultural teams 
they should increase the frequency of their communications than normal to aid in the development of team norms and to support open communication between team members (Cummings, 2007). In Duranti and Almeida's (2012) study on communication and technology, their findings suggest that the culture of the team member influenced their preference for which tool they use depending on the situation. They concluded that people from collectivist cultures preferred utilizing tools that were high in media richness like videoconferencing or teleconferencing versus those from individualistic cultures who were more comfortable with low media richness such as chat or instant messaging (Duranti \& Almeida, 2012). In Duran and Popescu (2014) study they offered a tactic that team leader can use when in a culturally diverse setting, to ensure that communications are understood is to ask for confirmation from team members or to use open questions that require a response to check their comprehension if the task (Duran \& Popescu, 2014).

\section{Strategies of CQ Leadership}

In GVTs the team members will likely have increased diversity than F2F teams, which means the members will have different backgrounds, first languages, different social and work norms, and come with their own unique experiences (Hosseini et al., 2013). In order for eleaders to be successful with a diverse team, they need to be able or be able to develop the four factors of CQ (Henderson et al, 2018; Rockstuhl, Seiler, Ang, Dyne \& Annen, 2011). In Hjaro and Puldelko's survey on 70 GVT members, they found evidence that supports the need of eleaders to have the knowledge of the values and beliefs and be able to adapt their behavior to the framework their employees' culture. They also imply that the only means that an e-leader can build social interactions in a multinational group is by showing sensitivity to their cultures (Hjaro \& Pudelko, 2010). E-leaders should have a higher degree of CQ in order to help their team 
resolve issues that may stem from cultural differences and they may need to address any stereotypes and substantiate the team norms (Hjaro \& Pudelko, 2010). Showing authentic interest in individual team member cultural background can improve morale and understanding (Zander, Mockaitis \& Butler, 2012). A few things e-leaders can do to display their vested interest into individual culture norms are knowing different holiday traditions and celebrations and making small gestures that are personal to the person's region (Henderson et al., 2018). Presbiteros (2016) study on CQ in virtual work that focal point was multicultural interactions support Moon's (2012) findings that the four factors of CQ were all significantly positively correlated to task performance.

CQ also has implications for training programs for the development of e-leaders. People that wish to lead a GVT should receive professional training to e-leaders that pays special attention to CQ-motivation could empower leaders to be aware of and supportive towards their team members cultural diversity (Henderson et al., 2018). Studies suggest that for managing culturally diverse teams the leaders are critical for their management and organizations should provide CQ training programs to enhance the leader's capabilities (Rosenauer et al., 2016).

\section{Traits and Characteristics for e-Leader Selection and Training}

Now that the prevailing attributes, skills, and behaviors of successful e-leaders have been identified, there is still the question of how organizations can use this knowledge to hire or train the people that are best suited to e-leadership. Studies vary in the methods they use for establishing the correlations of the factors of e-leadership but there is a noticeable trend in the literature. Overwhelmingly the information on CQ and personality trait connections find that there is a significant association between openness to experience and individuals with high CQ but there is disagreement on the role of agreeableness and extraversion in these studies (Ang, 
Dyne \& Koh, 2006; Li, Mobley \& Kelly, 2016; Depaula, Castillo, Cosentino, \& Azzollini, 2016). The studies that investigate the relationship between personality and transformational leadership have greater variability in their results possibly due to none of the studies being conducted in the same environment but some of the research has found that openness to experience and agreeableness are related to transformational leaders (Deinert, Homan, Boer, Voelpel \& Gutermann, 2015). Even less research has been conducted on the connection between CQ and transformational leadership, but such findings seem to indicate that CQ can be used as a predictor in these scenarios (Ismal, Reza \& Mahdi, 2012; Ramsay, Rutti, Lorenz \& Barakat, 2017; Woerkom, S.M. de Reuver, 2009). These studies, their methods, and generalizability to GVT leaders will be evaluated in the following sections.

\section{Assessing the Big Five}

The Big Five personality traits are commonly used taxonomy in empirical research. The framework is comprised of openness to experience, conscientiousness, extraversion, agreeableness, and neuroticism and was advanced by McCrae and Costa $(1985,1987)$. Most of the studies addressed in this review used the Big Five to test correlations with CQ and leadership styles (Ang, Dyne \& Koh, 2006; Deinert, Homan, Boer, Voelpel, \& Gutermann, 2015; Li, Mobley \& Kelly, 2016; Presbitero, 2016). It is widely used in research because of its versatility across cultures and reliability across various raters (McCrae \& Costa, 1987). The method of assessing or measuring the personality dimensions, however, varies from study to study, but all use the Big Five as their foundation. The NEO Five-Factor Inventory (NEO-FFI) published by Psychological Assessment Resources was used in Li, Mobley, and Kelly’s (2016) study. The Benet-Martinez and John's (1998) Big Five Inventory was used in Presbitero's (2016) study. 
Ang, Dyne, and Koh (2006) used the Personal Characteristics Inventory developed by Mount and Barrick, (1995).

\section{Personality in Relation to CQ}

In Ang, Dyne, \& Koh's, (2006) study they examined the relationship between the fourfactor model of cultural intelligence and the Big Five personality characteristics. This was the first study to examine the relationship of personality and CQ (Ang, Dyne, \& Koh, 2006) The four-factors of cultural intelligence as aforementioned are: metacognitive, cognitive, motivational, and behavioral. The results from the study place particular importance on openness to experience because their findings showed that it is a critical factor in an individual's ability to work successfully with someone with a dissimilar cultural background (Ang, Dyne, \& Koh, 2006). Out of the five personality factors only, openness to experience was significantly associated with all four of the CQ factors.

Presbitero's (2016) made a significant contribution to the literature on virtual multicultural interactions, particularly that the four-factor model of CQ is applicable in virtual settings. It investigated the associations between the four-factor model of CQ and the Big Five personality dimensions in a call center characterized by multicultural interactions, it revealed that extraversion and openness to experience were considerably related to cognitive, metacognitive, behavioral, and motivational CQ. Because this study was conducted with a multicultural setting it may arguably have stronger association to the environment of a GVT.

The studies discussed above individually evaluated the associations between dimensions of personality and CQ. In Li, Mobley, and Kelly's (2016) study they did an individual analysis using Ang and Van Dyne's (2007) 20-item 7-point scale to measure CQ and they tested how the personality factors interplay affected CQ. Their findings showed expected significant 
associations between openness to experience and all four factors of CQ; however, when agreeableness was low, these associations were reduced in three of the four CQ factors. The results suggest that individuals who are high in openness to experience but low in agreeableness may not perform as well in international settings.

\section{Personality in Relation to Leadership Style}

There have been a large number of studies conducted on transformational leadership and its impact on team performance, but these are primarily done in F2F teams. Despite the abundant research that identified transformational leadership and its subdimensions as the dominant successful e-leadership methodology, few quantitative studies have focused on personality correlations in multinational teams or in a virtual setting (Groves \& Feyerman, 2011). The tests that come up in the studies for testing transformational leadership is the various versions of Avolio and Bass's (2004) multifactor leadership questionnaire, Podsakoff, MacKenzie, Moorman, and Fetter's (1990) transformational leader behaviors inventory (TLI), and De Hoogh, Den Hartog and Koopman's (2004) questionnaire for charismatic leadership in organizations (Bealer \& Bhanugopan, 2014; Deinert, et al., 2015; Phaneuf, Boudrias, Rousseau \& Brunelle, 2016; Woerkom \& S.M. de Reuver, 2009)

Deinert, Homan, Boer, Voelpel, and Gutermann's (2015) study of the associations between the Big Five and transformational leadership was not conducted using a sample of GVTs, but it is still relevant to the applicability of the leadership style. The results of their study found that openness to experience was significantly and positively correlated to all four of transformational leadership subdivisions. The four sub-dimensions of transformational leadership are; idealized influence, inspirational motivation, intellectual stimulation, and individualized consideration. Agreeableness was positively correlated overall and had significant 
correlations to all the transformational leadership subdimensions with the exception of intellectual stimulation. Extraversion was positive overall and had significant links to idealized influence and inspirational motivation. Conscientiousness was positively correlated overall but only had a significant correlation to one sub-dimension, idealized influence.

A meta-analytic investigation by Derue, Nahrganag, Wellman and Humhrey (2011) took a comprehensive approach towards analyzing personality trait and behavioral theories of leadership. Specifically, the authors built an integrated model of the dominant leadership styles and tested how the different traits and behaviors interact to predict leader effectiveness. Their approach broke down aspects of transformational, transactional and other leadership styles into behavior categories such as task-oriented, relational-oriented, change-oriented, and passive leadership. Personality characteristics were also separated into categories with conscientiousness, openness to experience, and emotional stability going into task competence, and extraversion and agreeableness to interpersonal attributes. Their results showed that out of their 16 items for leader traits conscientiousness was the most consistent in predicting leader effectiveness. Out of the 15 items in their leader behavior paradigm, transformational leadership was the most consistent in predicting leader effectiveness.

\section{CQ in Relation to Transformational Leadership}

The similarities in transformational and CQ empirical research has led some researchers to theorize that they can be used to predict one another (Groves \& Feyerman, 2011). This has led to the emergence of a few studies that tested this possible association (Ismal, Reza, \& Mahdi, 2012; Keung \& Rockinson-Szapkin, 2013; Ramsey, Rutti, Lorenz, Barakat, \& Santana, 2017). The findings of these studies could have interesting implications towards the identification of successful e-leaders. For instance, Ramsay et al. (2017) sent and received responses from 190 
global leaders. The criteria they used to isolate these leaders were that they must be in a leadership position and that they must have global responsibilities, which they broke into four parts: 1) interact consistently with different cultures, 2) international travel requirement, 3) be an expatriate, 4) foreign team management, or manage clients, and suppliers from different countries (Ramsay et al., 2017). They investigated the association between overall CQ and overall transformational leadership using the 20-item CQ scale and the 23-item transformational leader's behaviors inventory, and they used international experience as a moderator. Their findings provide evidence that there is a positive association between transformational leadership and CQ and confirmed that international experience strengthens this relationship. In their posthoc analysis, they also noted that CQ independently impacted five of the six subdimensions of transformational leadership used in their study. The five that were positively impacted by high CQ were: determining and sharing a team vision, acting as a proper role model, promoting shared group objectives, expecting a high performance of the team, and supplying intellectual stimulation.

\section{Performance, Transformational Leadership, and Multicultural Personality}

Some research suggests that in multicultural organizations, cultural empathy, openmindedness, and social initiative can be used as predictors of high performing transformational leaders (Van Woerkom \& De Reuver, 2009). For Van Woerkom \& De Reuver's study (2009) their focus group was leaders on expatriate assignment and that were leaders of multicultural teams. Instead of using the Big Five, this study used a Multicultural Personality Questionnaire (MPQ) (Van der Zee and Van Oudenhoven, 2000), which consists of five factors: cultural empathy, open-mindedness, social initiative, emotional stability, and flexibility (Van Woerkom \& De Reuver, 2009). These variables are not dissimilar to the Big Five characteristics, but it adds 
a focus on the CQ of the leader which could prove useful in GVT research. Their study found that the higher cultural empathy, open-mindedness and social initiative a leader is the stronger the association is to transformational leadership (Van Woerkom \& De Reuver, 2009). They also found that the leaders that had a multicultural personality and were transformational leaders had higher performance appraisals (Van Woerkom \& De Reuver, 2009).

\section{The Moderating Role of Technology}

Technology is the primary medium that is utilized in GVTs, it is the sole way teams communicate, collaborate and accomplish project tasks. It is the basis and mediator for the rapid expansion of GVTs. The development of technology offers substantial benefits to businesses but it is inherently different than the office environment and should be recognized as such. Studies have shown that technology-enabled communications may increase perceived risks by team members and lesson the willingness of members to feel comfortable collaborating through different mediums (Breuer et al., 2016; Sarker et al., 2011). However, the use of technology that provides documentation of member and team interactions has been found to decrease the perceived risks of virtual work (Breuer et al., 2016). Tool preference and efficiency changes depending on the situation, for tasks that are complicated research points to using synchronous technology such as video conferencing, or conference calls (Deluca \& Valacich, 2006;

Weimann, Pollock, Scott, \& Brown, 2013). The probability that the team members will use multiple tools for a single task is high and efficiency depends on the integration of the tools (Weimann et al., 2013). E-leaders need to be well versed in using all the different media effectively and needs to establish norms, frequency, and conduct for each tool (Hambley et al., 2007). It is the e-leader's responsibility to ensure that all members are aligned with which tools 
can and will be used by the group, taking into consideration the different levels of expertise and availability of technology at each member location (Ferrel \& Kline, 2018).

\section{Communication and Technology}

Technology has the ability to communicate information between team members without intention or direct interactions. F2F communication is richer with non-verbal and auditory cues in comparison to technology-enabled communication (Lilian, 2014). Technology-enabled communication has a greater risk of information loss and misinterpretation because of the absence of nonverbal cues (Lilian, 2014). e-leaders need to develop communication skills such as online social opportunities that foster the collaboration of all members, that are not necessary for F2F settings (Lilian, 2014). Media richness is the ability of the communication tool to have the needed features to allow the shared understanding of equivocal issues (Huang et al., 2010). This medium should have the ability of immediate feedback, communication of multiple cues, and personalization (Huang et al., 2010).

Joking and kidding may not come across positively in a virtual setting where in F2F interactions this is generally a normal socialization practice this should be discouraged especially in mediums that do not allow for visualization of the other member (Greenburg et al., 2007).

\section{Technology Strategies}

The selection and use of tools are an important aspect to virtual teams and can influence the team's performance, cohesion, and satisfaction (Weimann et al., 2013). Multiple factors need to be considered when picking which tools individual preferences if it meets the requirements of the project, internet capabilities, tool training, and tool integration. If a new program or medium is going to be introduced to the team, training is a key to the team being willing to use the tool (Greenburg et al., 2007). Failure to provide training can result in decreased performance 
capabilities and delays in accomplishing the team project (Ferrell \& Kline, 2018; Greenburg et al., 2007). e-leaders need to ensure that members are cognizant of how they communicate through technology because of the ease of misinterpretation (Greenburg et al., 2007). For managing tasks there are tools available that allow for transparency of work in progress between all members; utilizing these tools has the added benefit of increasing team member satisfaction (Brueur et al., 2016). Having a contingency plan in place for members when the unavoidable event of technology-communication failure occurs is important for trust and for individuals to be able to continue task progression (Ford et al., 2017). When using technology such as teleconference the e-leader should look for participation from all members of the group (Hambley et al., 2007). In addition, leaders should monitor the conversation to ensure dominant personalities do not take over the conversation (Hambley et al., 2007), and encourage socialization or non-task related discussion in order to create personalization of the conversation (Hambley et al., 2007). Video conferencing is useful for complex tasks, and allows for the visualization of body language but should be used wisely for GVTs that are especially dispersed. Various time zones may make it difficult for all members to attend and rotating times for team meetings to accommodate for different time zones (Ford, et al., 2017; Hambley et al., 2007). Finally, leaders should ensure that all organizational information is available to all members and that they know how to access it (Ford et al., 2017).

\section{Discussion}

This thesis has identified what leader actions and behaviors have been isolated in previous research and assigned them to the established leadership styles where applicable. It also indicates that leaders will need to have certain abilities in order to be successful in GVTs. These include knowledge on how to foster trust, leveraging of technology and communication and how 
to interact with cultural diversity. This thesis offers strategies to e-leaders but it also points to research that certain personality traits may be indicative for e-leaders that are more suited to leading a GVT. There exists a multitude of questionnaires that have the ability to identify transactional, transformational, LMX and high CQ leaders, by isolating only the specific behaviors and actions outlined in this review there could be an effective method of identifying leaders that would be successful in managing GVTs.

Training is a frequent theme in the literature of GVTs, e-leaders should have training from organizational means for CQ development, transformational leadership style, and all other aspects of leading a GVT. It has been noted that GVTs are often less productive than their F2F counterparts, and it was found that there is a lac of training that addresses the challenges of working on a global team with only 22 percent of GVT members receiving any training (RW3 CultureWizard, 2016).

\section{Limitations of Present Review}

While reviewing the existing literature on virtual teams, I found that there was little on the associations between the Big Five personality characteristics, e-leadership and how they influence performance. The extant studies on this topic are in relation to the constructs identified as critical to e-leadership but they do not categorically address virtuality. Additionally, not all industries will present the same challenges in virtual settings. This review does not consider the factors of team size, demographics, or industry. Further, this review is limited to this arena and will not cover all possibilities and situations of leadership in GVTs.

Another limitation is that this research does nothing to address how leaders should select members of their virtual teams. There is a prevalent body of literature on this subject and does stand to have an impact on the success of an e-leader. Previous studies have shown that 
transformational leadership is not universally advantageous with all employees and can be dependent on the individual characteristics of team members (Hansbrough \& Schyns, 2018). Not all studies reviewed in this research identified the country of residence of the participants. This is important when considering the effects of inspirational motivation and transformational leadership effectiveness especially if participants are located within high-power distance cultures. The methods of team evaluation vary from study to study, and there are many different indicators of performance used to evaluate the effectiveness of the team leader. These can include but are not limited to cohesiveness, customer satisfaction, profitability, team effectiveness, performance evaluations, retention, employee satisfaction, and project completion (Coovert, et al., 2017; Van Woerkom \& De Reuver, 2009; Hambley, et al., 2007; Breuer,et al., 2016; Ford, et al., 2017)

While conducting this review, conflict management was brought in multiple instances as necessary skills for e-leadership. However, I did not fully explore this topic because it was only highlighted in less than ten percent of the articles analyzed. This does not mean that it is irrelevant to work in virtual teams, but for the sake of precision and succinctness, it was not included.

There also appears to be a general paucity of research investigating the four subdimensions of transformational leadership in the virtual environment. While a few were identified and accessed it is far from a fully explored topic, this gap leaves questions as to which of the behavioral components of transformational leadership are most advantageous to virtual teams.

Lastly, there is a lack of studies being conducted with the distinctive composition of GVTs. Few address the difference between a virtual team that is primarily composed of 
individuals with the same first language and culture and the increased necessity of CQ in global teams that are more diverse. Very few of the studies considered other variables that could affect the outcome of e-leaders and this will inevitably show some variation in results as studies continue in this emerging arena.

\section{Directions for Future Research}

Comprehensive test that encompasses all constructs of virtual work; trust, transformational leadership, technology, and CQ to evaluate their correlation to the Big Five personality factors. There already exist tests for leadership behaviors, cultural intelligence, and personality factors, by combining aspects from these individual tests research could sharpen the discourse communities understanding of virtual leadership. If testing confirms the findings presented here it could be used towards the hiring of a "best-fit" e-leader, to identify areas that leaders need to develop and towards the training of staff to get the most from their virtual workforce.

An example of one such survey would use constructs of personality that are consistent and able to identify individuals with the traits necessary for e-leadership. This would use a leadership dimension such as the MLQ, a personality questionnaire the Big Five, and a CQ component test for correlations to GVT performance. The findings from Van der Zee and Van Oudenhoven's (2009) survey confirmed that transformational leaders that had multicultural personalities received higher performance reviews. Expanding the leadership model, they used to also test for certain transactional traits aforementioned would contribute to the literature to confirm the findings presented here that using both leadership styles effects GVT performance. Avolio and Bass's (2004) MLQ seems best suited for a study of this type because it is a supported method for identifying transactional and transformational behaviors. There would also 
need to be a control in place to negatively associated the transactional actions and behaviors that are not beneficial in GVTs such as passive management. By using the actions and behaviors that have been found as essential to GVT leadership outlined in this research there could be the potential towards the testing for the best fit e-leader.

Another contribution to the discourse community would be a study targeted to top performing leaders of GVT's and the members. A significant portion of the findings presented here were of virtual teams, undergraduate students, white papers, case studies, and presentations of findings from literature reviews. While these offer insight and valuable information to the knowledge on e-leadership they are not quantifiable studies that are replicable and incorporate all of the necessary constructs of GVT e-leadership. DeRosa's study (2011) is a good example of a survey method for identifying success factors in a virtual team that addressed many aspects of eleadership such as communication, overcoming challenges, leadership behaviors, technology and training. They distributed an online virtual team inventory assessing six dimensions of performance and received a high overall reliability. However, the study is limited because it was conducted with a variety of team types that had virtual operations but had F2F interactions frequently and not all teams analyzed were global. If this survey was distributed to target only GVTs it could offer the specific insights that are underdeveloped in GVT studies.

An additional theme that was noted in this review was that researchers brought up the age of individuals working in virtual teams and the possible implications that younger generations could bring to GVTs. (Iorio \& Taylor, 2015). The generations that were brought up with the technology used in virtual teams may make them better suited to working on these teams and research as of yet has not conducted studies where the teams were primarily composed of those from this generation. 


\section{Conclusion}

The overall purpose of this thesis is to give insight to organizations through the analysis of the existing literature on leading GVTs. It is recognized that virtual teams are more challenging to lead and are often found to be less productive than F2F teams. Companies invest considerable resources in their GVTs, they can possibly improve their returns by employing training programs that are specific to the challenges faced by global virtual leaders and they can try to ensure they hire the right person for the position. As the research on GVTs continues to grow an appropriate model of predicting those with e-leadership aptitude will be established but first there needs to be consensus as to what attributes, behaviors, personality characteristics, and interpersonal skills are required for the position. The findings in this thesis offers a unification of the research on this subject has found thus far and also may serve as a strategy tool for leaders of GVTs. This research also suggests ways that future research can expand to include the gaps in the literature on leading GVTs. 


\section{References}

Anantatmula, V., \& Thomas, M. (2010). Managing global projects: A structured approach for better performance. Project Management Journal, 41(2), 60-72.

Andressen, P., Konradt, U., \& Neck, C. P. (2012). The relation between self-leadership and transformational leadership: Competing models and the moderating role of virtuality. Journal of Leadership \& Organizational Studies, 19(1), 68-82.

Ang, S., \& Van Dyne, L. (2008). Handbook of cultural intelligence theory, measurement, and applications. Armonk, NY: M.E. Sharpe.

Ang, S., Van Dyne, L., \& Koh, C. (2006). Personality correlates of the four-factor model of cultural intelligence. Group \& Organization Management, 31(1), 100-123

Avolio, B., Bass, B., \& Jung, D. (1999). Re-examining the components of transformational and transactional leadership using the Multifactor Leadership Questionnaire. Journal of Occupational and Organizational Psychology, 72(4), 441-462.

Avolio, B., \& Bass, B., (2004). Multifactor leadership questionnaire (MLQ). Mind Garden, 29.

Balthazard, P., Waldman, D., \& Warren, J. (2009). Predictors of the emergence of transformational leadership in virtual decision teams. The Leadership Quarterly, 20(5), 651-663.

Bass, B. (1985). Leadership and performance beyond expectations. New York : London: Free Press ; Collier Macmillan.

Bass, B., \& Avolio, B. (1994). Improving organizational effectiveness through transformational leadership. Thousand Oaks: Sage Publications.

Bealer, D., \& Bhanugopan, R. (2014). Transactional and transformational leadership behavior of 
expatriate and national managers in the UAE: A cross-cultural comparative analysis. The International Journal of Human Resource Management, 25(2), 293-316.

Bell, B., \& Kozlowski, S. (2002). A typology of virtual teams: Implications for effective leadership. Group \& Organization Management, 27(1), 14-49.

Benet-Martínez, V., \& John, O. (1998). Los Cinco Grandes across cultures and ethnic groups: Multitrait multimethod analyses of the Big Five in Spanish and English. Journal of Personality and Social Psychology, 75(3), 729-750.

Breuer, C., Hüffmeier, J., \& Hertel, G. (2016). Does trust matter more in virtual teams? A metaanalysis of trust and team effectiveness considering virtuality and documentation as moderators. Journal of Applied Psychology, 101(8), 1151-77.

Burns, J. (1978). Leadership (1st ed., Cass Canfield book). New York: Harper \& Row.

Cascio, W., \& Shurygailo, S. (2003). E-leadership and virtual teams. Organizational dynamics.

Chang, H., Hung, C., \& Hsieh, H. (2014). Virtual teams: Cultural adaptation, communication quality, and interpersonal trust. Total Quality Management \& Business Excellence, 25(11-12), 1318-1335.

Chang, W.-L., \& Lee, C.-Y. (2013). Virtual team e-leadership: The effects of leadership style and conflict management mode on the online learning performance of students in a business-planning course. British Journal of Educational Technology, 44(6), 986-999.

Choi, O. K., \& Cho, E. (2019). The mechanism of trust affecting collaboration in virtual teams and the moderating roles of the culture of autonomy and task complexity. Computers in Human Behavior, 91, 305-315.

Coovert, M., Miller, E., \& Bennett, W. (2017). Assessing trust and effectiveness in virtual 
teams: Latent growth curve and latent change score models. Social Sciences, 6(3), 87.

Curşeu, P., \& Schruijer, S. (2010). Does conflict shatter trust or does trust obliterate

conflict? Revisiting the relationships between team diversity, conflict, and trust. Group Dynamics: Theory, Research, and Practice, 14(1), 66.

Daim, T., Ha, A., Reutiman, S., Hughes, B., Pathak, U., Bynum, W., \& Bhatla. A. (2011). Exploring the communication breakdown in global virtual teams. International Journal of Project Management, 30(2), 199-212.

De Hoogh, A., Den Hartog, D., \& Koopman, P. (2005). Linking the Big Five-Factors of personality to charismatic and transactional leadership; Perceived dynamic work environment as a moderator. Journal of Organizational Behavior, 26(7), 839-865.

De Jong, B. A., \& Elfring, T. (2010). How does trust affect the performance of ongoing teams? The mediating role of reflexivity, monitoring, and effort. Academy of Management Journal, 53(3), 535-549.

Deinert, A., Homan, A., Boer, D., Voelpel, S., \& Gutermann, D. (2015). Transformational leadership sub-dimensions and their link to leaders' personality and performance. The Leadership Quarterly, 26(6), 1095-1120.

Deluca, D., \& Valacich, J. (2006). Virtual teams in and out of synchronicity. Information Technology \& People, 19(4), 323-344.

Dennis, D., Meola, D., \& Hall, M.J. (2013). Effective leadership in a virtual workforce: Ideas and insights on the skills needed for leaders of remote employees. $T+D, 67(2), 46-51,8$

Depaula, P., Castillo, S., Cosentino, A., \& Azzollini, S. (2016). Personality, character strengths 
and cultural intelligence: "Extraversion" or "openness" as further factors associated to the cultural skills? Avances En Psicología Latinoamericana, 34(2), 415-436.

DeRosa, D. (2011). Collaborating from a distance: Success factors of top-performing virtual teams. (Report). International Journal of E-Collaboration, 7(3), 43-54.

Derue, S., Nahrgang, J., Wellman, N., \& Humphrey, S. (2011). Trait and behavioral theories of leadership: An integration and meta-analytic test of their relative validity. Personnel Psychology, 64(1), 7-52.

Derven, M. (2016). Four drivers to enhance global virtual teams. Industrial and Commercial Training, 48(1), 1-8.

Duran, V., \& Popescu, A.D. (2014). The challenge of multicultural communication in virtual teams. Procedia - Social and Behavioral Sciences, 109(C), 365-369.

Duranti, C., \& de Almeida, F. (2012). Is more technology better for communication in international virtual teams? International Journal of e-Collaboration (IJeC), 8(1), 36-52.

Eidson, C. (2011). Six things managers need to know. (virtual teams). Agency Sales Magazine, 41(12), 30 .

Erez, M., Lisak, A., Harush, R., Glikson, E., Nouri, R., \& Shokef, E. (2013). Going global: Developing management students' cultural intelligence and global identity in culturally diverse virtual teams. Academy of Management Learning \& Education, 12(3), 16-41

Eseryel, Uy, \& Eseryel, D. (2013). Action-embedded transformational leadership in selfmanaging global information systems development teams. Journal of Strategic Information Systems, 22(2), 103-120.

Ferrell, J., \& Kline, K. (2018). Facilitating trust and communication in virtual teams. People 
\& Strategy, 41(2), 30-35.

Ford, R., Piccolo, R., \& Ford, L. (2017). Strategies for building effective virtual teams: Trust is key. Business Horizons, 60(1), 25-34.

Gajendran, R. S., \& Joshi, A. (2012). Innovation in globally distributed teams: The role of LMX, communication frequency, and member influence on team decisions. Journal of Applied Psychology, 97(6), 1252.

Germain, M. (2011). Developing trust in virtual teams. Performance Improvement Quarterly, 24(3), 29-54.

Germain, M., Mcguire, D., Bennett, E., \& Mcwhorter, R. (2014). The Role of Swift Trust in Virtual Teams and Implications for Human Resource Development. Advances in Developing Human Resources, 16(3), 356-370.

Graen, G. B., \& Uhl-Bien, M. (1995). Relationship-based approach to leadership: Development of leader-member exchange (LMX) theory of leadership over 25 years: Applying a multilevel multi-domain perspective. The leadership quarterly, 6(2), 219-247.

Greenberg, P., Greenberg, R., \& Antonucci, Y. (2007). Creating and sustaining trust in virtual teams. Business Horizons, 50(4), 325-333.

Groves, K., Feyerman, A., (2011). Leader cultural intelligence in context: Testing the moderating effects of team cultural diversity on leader and team performance. Group and Organization Management, 35(5), 535-566.

Guinalíu, M., \& Jordán, P. (2016). Building trust in the leader of virtual work teams. Spanish Journal of Marketing-ESIC, 20(1), 58-70. 
Hajro, A., Pudelko, M., Reiche, B., \& Carr, C. (2010). An analysis of core-competences of successful multinational team leaders. International Journal of Cross Cultural Management, 10(2), 175-194.

Hambley, L., O'Neill, T., \& Kline, T. (2007). Virtual team leadership: Perspectives from the field. International Journal of E-Collaboration, 3(1), 40-64.

Hansbrough, T. K., \& Schyns, B. (2018). The appeal of transformational leadership. Journal of Leadership Studies, 12(3), 19-32.

Henderson, L., Stackman, R., \& Lindekilde, R. (2018). Why cultural intelligence matters on global project teams. International Journal of Project Management, 36(7), 954-967.

Hoch, J., \& Kozlowski, S. (2014). Leading virtual teams: Hierarchical leadership, structural supports, and shared team leadership. Journal of applied psychology, 99(3), 390.

Hosseini, M.R., Zuo, J., Chileshe, N., Baroudi, B. (2013). A conceptual meta-framework for managing multicultural global virtual teams. Int. Journal of Networking and Virtual Organizations, 12(4), 310-330.

Huang, R., Kahai, S., \& Jestice, R. (2010). The contingent effects of leadership on team collaboration in virtual teams. Computers in Human Behavior, 26(5), 1098-1110.

Iorio, J., \& Taylor, J. (2015). Precursors to engaged leaders in virtual project teams. International Journal of Project Management, 33(2), 395-405.

Ismail, A. M., Reza, R., \& Mahdi, S. (2012). Analysis the relationship between cultural intelligence and transformational leadership. International Journal of Business and Social Science, 3(14), 252-261. 
Joshi, A., Lazarova, M. B., \& Liao, H. (2009). Getting everyone on board: The role of inspirational leadership in geographically dispersed teams. Organization science, 20(1), 240-252.

Keung, E., \& Rockinson-Szapkiw, A. (2013). The relationship between transformational leadership and cultural intelligence: A study of international school leaders. Journal of Educational Administration, 51(6), 836-854.

Kuruppuarachchi, P. (2009). Virtual team concepts in projects: A case study. Project Management Journal,40(2), 19-33.

Lauring, J., \& Jonasson, C. (2018). Can leadership compensate for deficient inclusiveness in global virtual teams? Human Resource Management Journal, 28(3), 392-409.

Lee-Kelley, L., \& Sankey, T., (2008). Global virtual teams for value creation and project success: A case study. International Journal of Project Management, 26(1), 51-62.

Li, M., Mobley, W., \& Kelly, A. (2016). Linking personality to cultural intelligence: An interactive effect of openness and agreeableness. Personality and Individual Differences, 89, 105-110.

Liao, C. (2017). Leadership in virtual teams: A multilevel perspective. Human Resource Management Review, 27(4), 648-659.

Lilian, S. (2014). Virtual teams: Opportunities and challenges for e-Leaders. Procedia - Social and Behavioral Sciences, 110(C), 1251-1261.

Maduka, N., Edwards, H., Greenwood, D., Osborne, A., \& Babatunde, S. (2018). Analysis of competencies for effective virtual team leadership in building successful organisations. Benchmarking: An International Journal, 25(2), 696-712. 
Marlow, S., Lacerenza, C., \& Salas, E. (2017). Communication in virtual teams: A conceptual framework and research agenda. Human Resource Management Review, 27(4), 575-589.

Mayer, R., Davis, J., \& Schoorman, F. (1995). An integrative model of organizational trust. The Academy of Management Review, 20(3), 709-734. Retrieved from http://www.jstor.org.proxy.lib.pdx.edu/stable/258792

Mccrae, R., \& Costa, P. (1985). Updating Norman's "Adequate Taxonomy": Intelligence and personality dimensions in natural language and in questionnaires. Journal of Personality and Social Psychology, 49(3), 710-721.

McCrae, R., \& Costa, P. (1987). Validation of the five factor model of personality across instruments and observers. Journal of Personality and Social Psychology, 52, 81-90.

Mockaitis, A., Zander, L., \& De Cieri, H. (2018). The benefits of global teams for international organizations: HR implications. The International Journal of Human Resource Management, 29(14), 2137-2158.

Moon, T. (2013). The effects of cultural intelligence on performance in multicultural teams. Journal of Applied Social Psychology, 43(12), 2414-2425.

Mount, M., \& Barrick, M. (1995). The Big Five personality dimensions: Implications for research and practice in human resources management. Research in personnel and human resources management, 13(3), 153-200.

Peters, L., \& Karren, R. (2009). An examination of the roles of trust and functional diversity on virtual team performance ratings. Group \& Organization Management,34(4), 479-504.

Phaneuf, J.E., Boudrias, J.S., Rousseau, V., \& Brunelle, E. (2016). Personality and transformational leadership: The moderating effect of organizational context. Personality 
and Individual Differences, 102, 30-35.

Podsakoff, P., Mackenzie, S., Moorman, R., \& Fetter, R. (1990). Transformational leader behaviors and their effects on followers' trust in leader, satisfaction, and organizational citizenship behaviors. The Leadership Quarterly, 1(2), 107-142.

Polzer, J., Crisp, C., Jarvenpaa, S., \& Kim, J. (2006). Extending the Faultline Model to geographically dispersed teams: How colocated subgroups can impair group functioning. The Academy of Management Journal,49(4), 679-692.

Poulsen, S., \& Ipsen, C. (2017). In times of change: How distance managers can ensure employees' wellbeing and organizational performance. Safety science, 100, 37-45.

Presbitero, A. (2016). Cultural intelligence (CQ) in virtual, cross-cultural interactions: Generalizability of measure and links to personality dimensions and task performance. International Journal of Intercultural Relations, 50, 29-38.

Presbitero, A., \& Toledano, L. (2018). Global team members' performance and the roles of cross-cultural training, cultural intelligence, and contact intensity: The case of global teams in IT offshoring sector. The International Journal of Human Resource Management,29(14), 2188-2208.

Purvanova, R., \& Bono, J. (2009). Transformational leadership in context: Face-to-face and virtual teams. The Leadership Quarterly, 20(3), 343-357.

Rack, O., Ellwart, T., Hertel, G., \& Konradt, U. (2011). Team-based rewards in computer-mediated groups. Journal Of Managerial Psychology, 26(5), 419-438.

Ramsey, J., Rutti, R., Lorenz, M., Barakat, L., \& Sant'anna, A. (2017). Developing global transformational leaders. Journal of World Business, 52(4), 461-473.

Rockstuhl, T., Seiler, S., Ang, S., Van Dyne, L., \& Annen, H. (2011). Beyond general 
intelligence (IQ) and emotional intelligence (EQ): The role of cultural intelligence (CQ) on cross-border leadership effectiveness in a globalized world. Journal of Social Issues, 67(4), 825-840.

Rosenauer, D., Homan, A., Horstmeier, C., \& Voelpel, S. (2016). Managing nationality diversity: The interactive effect of leaders' cultural intelligence and task interdependence. British Journal of Management, 27(3), 628-645.

RW3 CultureWizard. (2018). Trends in global virtual teams report. Retrieved June 27, 2019 from https://www.rw-3.com/

Sarker, S., Ahuja, M., Sarker, S., \& Kirkeby, S. (2011). The role of communication and trust in global virtual teams: A social network perspective. Journal of Management Information Systems, 28(1), 273-310.

Van der Zee, K., and Van Oudenhoven, J.P. 2000. The Multicultural Personality Questionnaire: A multidimensional instrument of multicultural effectiveness. European Journal of Personality, 14: 291-309.

Van Dyne, L., Ang, S., Ng, K. Y., Rockstuhl, T., Tan, M. L., \& Koh, C. (2012). Sub-dimensions of the four factor model of cultural intelligence: Expanding the conceptualization and measurement of cultural intelligence. Social and personality psychology compass, 6(4), 295-313.

Van Woerkom, M., \& De Reuver, R. (2009). Predicting excellent management performance in an intercultural context: A study of the influence of multicultural personality on transformational leadership and performance. The International Journal of Human Resource Management, 20(10), 2013-2029. 
Väyrynen, K., \& Aalto, J. (2013). The organization's role in global virtual team leaders' possibilities to successfully lead the team across its lifecycle. In 2013 46th Hawaii International Conference on System Sciences (pp. 386-395). IEEE.

Verburg, R. M., Bosch-Sijtsema, P., \& Vartiainen, M. (2013). Getting it done: Critical success factors for project managers in virtual work settings. International Journal of Project Management, 31(1), 68-79.

Weimann, P., Pollock, M., Scott, E., \& Brown, I. (2013). Enhancing team performance through tool use: How critical technology-related issues influence the performance of virtual project teams. IEEE Transactions on Professional Communication, 56(4), 332-353.

Zander, L., Mockaitis, A., \& Butler, C. (2012). Leading global teams. Journal of World Business, 47(4), 592-603.

Zander, L., Zettinig, P., \& Mäkelä, K. (2013). Leading global virtual teams to success. Organizational Dynamics, 42(3), 228-237. 